\title{
Employer's information and promotion-seeking activities
}

\author{
Gil S. Epstein* \\ Department of Economics, Bar-Ilan University, Israel and CReAM, London and IZA, Bonn
}

Received: 12 August 2012

Revised: 4 November 2012

Accepted: 18 November 2012

\begin{abstract}
This paper presents a model in which promotion of employees within the internal firm hierarchy is determined by the individuals' allocation of time between promotion/rent-seeking and productive activity. We consider the effect of an increase in the employer's knowledge (information) regarding the employees' productivity levels on the total time spent by the workers in non-productive promotion-seeking activities.
\end{abstract}

Keywords: promotion-seeking activities, contest, knowledge

JEL Classification Codes: D21, J22, D72

\section{Introduction}

Many firms have difficulty in assessing their employees' contribution to the total output and profits (Radner, 1993). Since the employer does not have full knowledge of the employees' productivity levels, employees may attempt to influence the employer's decision regarding promotion. Milgrom and Robert (1992) define such activities as "influence costs", which may be regarded as rent-seeking (to earn rents in the form of promotion). Rent and promotionseeking are non-productive activities which are costly to the firm. The rents in the firm become, therefore, contestable. ${ }^{1}$

\footnotetext{
*E-mail: gil.epstein@biu.ac.il.

Citation: Epstein, G.S. (2012) Employer's information and promotion-seeking activities, Economics and Business Letters, 1(4), 21-32.

${ }^{1}$ It is not clear whether the employer designs a rent-promotion - seeking contest or not however empirical studies and others such as Cleveland and Murphy (1992), Altman, Vanlenzi and Hodgettes (1985), Tziner (1999) have shown that employees invest in non-productive activities in order to increase their performance appraisal and believe that such activities will increase the probability of being promoted. Moreover, Tziner, Latham, Prince and Haccoum (1996) developed an instrument (PCPAQ) capable of quantitatively measuring the extent to which specific political considerations affect performance appraisal. In contrast to the above mentioned papers, this paper looks at the investment in non-productive and productive activities as substitutes and considers the employee's strategic time and effort invested in these activities.
} 
Many firms invest time and resources to gain more information regarding their workers' productivity levels and their contribution to the firm's output and profits. However, it is not clear that increasing the information, available to the manager, would actually lead to a decrease in the workers' total investment in non-productive rent and promotion-seeking activities. This paper addresses the issue.

The model considers a population of employees differentiated in terms of productivity and rent-seeking abilities. The firm's structure is a pyramid: with decreasing numbers of employees at the higher internal hierarchy levels, and only one incumbent at the top. Internal rent-seeking for promotion takes place on each of the firm's rung.

The literature widely discusses the way managers advance, via competition and through the firm's ranks (see, for example, Beckmann 1978). A career path is the outcome of competition among peers with the objective of advancing to higher rungs, and, correspondingly, more remunerative positions, during the life cycle. Successful contestants seek greater prosperity and further promotion at the expense of production. This is possible because of the ambiguities in measuring the individual's contribution to output (see Radner 1993). In this context, this paper points out the prominent role of rents and how rent-seeking influences promotion prospects.

Fama (1980) attempts to explain how the separation of security ownership and control, typical of large corporations, can be an efficient form of economic organization. He first sets aside the presumption that a corporation has owners in any meaningful sense. The entrepreneur is also laid to rest, at least for the purposes of the large modern corporation. The two functions usually attributed to the entrepreneur -management and risk bearing- are treated as naturally separate factors within the set of contracts called a firm. The firm is disciplined by competition from other firms, which forces the evolution of devides for efficiently monitoring the performance of the entire team and of its individual members. Individual participants in the firm, and in particular its managers, face both the discipline and opportunities provided by the markets for their services, both within and outside the firm.

The model presented here uses the same concept of hierarchical rent-seeking as Hillman and Katz (1987). They evaluated social losses, due to resources, to contest a bribe transferred through a hierarchy. In the Hillman-Katz model, the rent enters the hierarchy exogenously. In my model of a hierarchical firm, the value of the rent is endogenous, reflecting the incentives within the firm to divide time between rent-seeking and productive activity, and, in turn, the heterogeneous characteristics of firm's employees as rent-seekers and the internal firm structure.

Lazear and Rosen (1981) and Rosen (1986) and Lazear (1996 and references within), in papers along similar lines, investigated the incentives of prizes increasing survival in sequential elimination events. The most highly qualified contestant is determined by tournament. Success is based on "survival of the fittest" in maintaining "quality of play" as the game progresses. Their models identify the unique role of top-ranking prizes in maintaining performance incentives in career and other survival games: the equilibrium reward structure favors the top-ranking prizes, encouraging competitors to aspire to further heights, regardless of past achievements. By contrast, in the present model, the employer cannot fully assess productivity and the outcome of promotion contest is not necessarily the most efficient solution. Moreover, activities to gain promotion are non-productive, rather than productive, as in the other examples in the above-mentioned papers.

It is assumed that the employer does not have full information regarding the productivity levels of the workers and cannot distinguish between the workers' rent seeking activities and productive activities of the workers. Given that the workers are not identical, it is shown that 
as the employer's information regarding the workers' productivity levels increases, nonproductive activities to earn promotion increase rather than decrease. The reason behind this result seems to be that, as the information available to the employer increases, workers who have more to hide would, therefore, have to invest more time and effort to convince the manager they are worthy of promotion. However, at a sufficiently high information level, the total promotion activities would decrease.

First, a general model and results are presented. These are then illustrated using the Luce's (Multinomial) Logit model.

\section{The model}

\section{Overview}

The model has the following characteristics. Two non-identical risk-neutral employees seek to maximize their expected incomes over two periods. The firm also has two hierarchical levels. ${ }^{2}$ Contesting promotion is costly in time and loss of income, since productive work is directly rewarded, but not the time spent in (self)-promotional activities. The benefits to workers of ingratiating themselves via rent-seeking and contributing to the firm's output differ. A worker's income is determined by productivity level plus rents accruing at various rungs of the hierarchy.

The employer cannot distinguish precisely between the workers' rent-seeking and the productive activities, thereby enabling workers to compete for rents and promotion at the various rungs of the firm. ${ }^{3}$ If such a distinction were possible, the employer would promote the most productive workers.

Our objective is to gain insight into how the level of information available to the employer regarding the workers' productivity affects the firm's total promotion-seeking activities.

\section{Structure of the model}

In the first period, while on the first rung, employees can choose to compete in order to reach a higher position in the firm. The worker who loses (or did not enter the contest) continues working on the same rung as before the contest. The employee winning the competition is promoted in the second period.

Worker $i$ 's productivity level is denoted by $v_{i}(i=1,2)$, which defines the absolute productive efficiency per time unit. The worker's earnings on the second rung are denoted by $p_{i} \quad(i=1,2)$. The income per unit of labor is an increasing function of an individual's productivity and promotion-seeking ability, $d_{i}$. Thus, worker's earnings are determined by productivity levels plus the income from rent seeking.

Each worker is endowed with a certain amount of labor time, normalized to unity, which is allocated between productive activities $A_{i}$ and time spent in rent seeking $L_{i}$ :

$$
A_{i}+L_{i}=1
$$

In the first period, rent-seeking activities are divided into two parts, according to whether they are directed toward: (1) promotion, $L_{i}^{1}$; or (2) an increase in income, $L_{i}^{2}$. A worker's

\footnotetext{
${ }^{2}$ The results may be generalized to a larger number of rungs within a firm and to a declining number of employees on climbing the rungs of the firm's ladder.

${ }^{3}$ See for example, Milgrom and Roberts (1992) and Epstein and Spiegel (1997, 2001). 
income on the first rung is the sum of real contribution to the firm, $v_{i}\left(1-L_{i}^{1}-L_{i}^{2}\right)$, and income generated by rent seeking, $R_{i}\left(v_{i}, L_{i}^{2}\right)$, assuming that $\frac{\partial R_{i}\left(v_{i}, L_{i}^{2}\right)}{\partial L_{i}^{2}}>0$ and $\frac{\partial^{2} R_{i}\left(v_{i}, L_{i}^{2}\right)}{\partial\left(L_{i}^{2}\right)^{2}}<0$.

Regardless of whether they win or lose the contest, workers return to rent-seeking in order to increase their present income on a given rung. In the first period, the worker's income may be expressed as: ${ }^{4}$

$$
I_{i}=v_{i}\left(1-L_{i}^{1}-L_{i}^{2}\right)+R_{i}\left(v_{i}, L_{i}^{2}\right)
$$

Let $P r_{i}$ denote the probability of worker $i$ winning the contest and receiving an income $p_{i}\left(v_{i}\right)$ (hereinafter $\left.p_{i}\right)$ in the second period. The probability of losing the contest is $\left(1-P r_{i}\right)$, as a result of which a worker would earn an income $f_{i}\left(v_{i}\right)$ (hereinafter $\left.f_{i}\right)$ in the second period. ${ }^{5}$

To simplify, but without loss of generality, let the discount factor be one. Worker i's expected income/utility is, then, given by: ${ }^{6}$

$$
\begin{aligned}
E\left(I_{i}\right) & =v_{i}\left(1-L_{i}^{1}-L_{i}^{2}\right)+R_{i}\left(v_{i}, L_{i}^{2}\right)+f_{i}\left(1-\operatorname{Pr}_{i}\right)+p_{i} \operatorname{Pr}_{i} \\
& =v_{i}\left(1-L_{i}^{1}-L_{i}^{2}\right)+R_{i}\left(v_{i}, L_{i}^{2}\right)+f_{1}+\left(p_{i}-f_{i}\right) \operatorname{Pr}_{i}
\end{aligned}
$$

\subsection{The Information Structure}

Consider an employer choosing which employees to promote. Neoclassical economic theory assumes a utility allowing the employer to rank these alternatives and choose the highest ranked. Some psychologists (e.g., Luce (1959), Tversky (1969) and (1972)) criticized this deterministic approach, arguing that the outcome should be viewed as a probabilistic process. According to this approach, utility is deterministic, but the choice process is probabilistic. The employer does not necessarily choose the alternative with the highest utility, and there is some probability that various other possible alternatives would be chosen. A model of "bounded rationality" along these lines was proposed by Luce (1959) (see also Sheshinski (2002)). Luce showed that if the probabilities of making various choices satisfy a certain axiom (the choice axiom), a utility scale may be defined over the alternatives, such that the choice probabilities may be derived from such scales and utilities.

The contest presented below may not be designed by the employer rather it could be that the employees believe that such a contest exists. In the literature, it has been shown that workers invest time in non-productive activities - "political activities" which they believe increase the probability of being promoted (see for example Cleveland and Murphy, 1992, Altman, Vanlenzi and Hodgetts, 1985 and Tziner 1999). Thus even though, from the employer's point of view, the contest does not exist it may well exist in the eyes of the employees and the employees invest accordingly in such non-productive activities.

\footnotetext{
${ }^{4}$ It is clear that the employer could not create a contest which would promote the productive employee by promoting the one with the highest wage in the first period, since this might itself be the result of rent-seeking activity.

${ }^{5}$ Using the notation set above $f_{i}=v_{i}\left(1-L_{i}\right)+R_{i}\left(v_{i}, L_{i}\right)$, however, there is no advantage at this stage of breaking $f$ up into its two components.

${ }^{6}$ The model can be described as a one period model in which each period an employee can either get low or high outcome where the high outcome is a function of past promotion seeking activity and probability.
} 
Let us look at the broad picture and derive some general results. Later in the paper, a more restricted formulation of the promotion probability giving more specific results is considered.

\subsubsection{The general case}

Workers seek to maximize their expected income/utility through their choice of investment levels in promotion-seeking activities. The expected income is determined by the Nash equilibrium choices of promotion/rent-seeking activities, which, for worker $i$, follows from:

$$
\begin{gathered}
G_{i}=\frac{\partial E\left(I_{i}\right)}{\partial L_{i}^{1}}=-v_{i}+\left(p_{i}-f_{i}\right) \frac{\partial \operatorname{Pr}_{i}}{\partial L_{i}^{1}}=0 \quad \forall i=1,2 \\
D_{i}=\frac{\partial E\left(I_{i}\right)}{\partial L_{i}^{2}}=-v_{i}+\frac{\partial R_{i}\left(v_{i}, L_{i}^{2}\right)}{\partial L_{i}^{2}}=0 \quad \forall i=1,2
\end{gathered}
$$

Note that the $L_{i}{ }^{1}$ values are given by solving equations (4) and (5) for both players. The probability of promotion is assumed to be a function of: $a$. the investment levels of both workers in promotion-seeking activities, $L_{i} ; b$. their productivity levels, $v_{i}$, and $c$. The amount of information available to the employer regarding the workers' productivity, $\alpha$ (assuming the employer's information level for both workers is the same) is such that: $\frac{\partial \operatorname{Pr} o b_{i}\left(L_{i}{ }^{1}, L_{j}{ }^{1}\right)}{\partial L_{i}{ }^{1}}>0, \frac{\partial \operatorname{Pr} o b_{i}\left(L_{i}{ }^{1}, L_{j}{ }^{1}\right)}{\partial L_{j}}<0, \frac{\partial \operatorname{Pr} o b_{i}\left(L_{i}{ }^{1}, L_{j}{ }^{1}\right)}{\partial v_{i}}>0, \frac{\partial \operatorname{Pr} o b_{i}\left(L_{i}{ }^{1}, L_{j}{ }^{1}\right)}{\partial v_{j}}<0$

and $\operatorname{Pr} o b_{i}\left(L_{i}{ }^{1}, L_{j}{ }^{1}\right) \underset{\alpha \rightarrow \infty}{\rightarrow} 1$ for $v_{i}>v_{j}$ (alternatively, the manager has sufficient information to promote the more productive worker). Moreover, the marginal effect of the probability is assumed to decrease as the different variables increase $\left(\frac{\partial^{2} \operatorname{Pr} o b_{i}\left(L_{i}{ }^{1}, L_{j}{ }^{1}\right)}{\partial L_{i}{ }^{2}}<0\right){ }^{7}$. It is easy to show that second-order conditions are verified.

The Nash equilibrium for the determination of investment levels in promotion activities can be shown to satisfy the following:

$$
\frac{\partial L_{i}{ }^{1}}{\partial \alpha}=\frac{\frac{\partial G_{i}}{\partial L_{j}{ }^{1}} \frac{\partial G_{j}}{\partial \alpha}-\frac{\partial G_{j}}{\partial L_{j}{ }^{1}} \frac{\partial G_{i}}{\partial \alpha}}{\frac{\partial G_{i}}{\partial L_{i}{ }^{1}} \frac{\partial G_{j}}{\partial L_{j}{ }^{1}}-\frac{\partial G_{j}}{\partial L_{i}{ }^{1}} \frac{\partial G_{i}}{\partial L_{j}{ }^{1}}} \text { and } \frac{\partial L_{j}{ }^{1}}{\partial \alpha}=\frac{\frac{\partial G_{j}}{\partial L_{i}{ }^{1}} \frac{\partial G_{i}}{\partial \alpha}-\frac{\partial G_{i}}{\partial L_{i}{ }^{1}} \frac{\partial G_{j}}{\partial \alpha}}{\frac{\partial G_{i}}{\partial L_{i}{ }^{1}} \frac{\partial G_{j}}{\partial L_{j}{ }^{1}}-\frac{\partial G_{j}}{\partial L_{i}{ }^{1}} \frac{\partial G_{i}}{\partial L_{j}{ }^{1}}}
$$

This paper asks the question: what is the effect of an increase in the employer's knowledge, $\alpha$, regarding the total investment level on the firm's promotion-seeking activities $L_{1}{ }^{1}+L_{2}{ }^{1}{ }^{8}$ Using (4) and (6), gives:

${ }^{7}$ The function $\operatorname{Prob} b_{\mathrm{i}}\left(L_{i}, L_{j}\right)$ is usually referred to as a contest-success-function (CSF). The functional forms of the CSF's commonly assumed in the literature, see Nitzan (1994), Skaperdas (1996), Epstein and Nitzan $(2004,2007)$ and Epstein and Mealem (2012) satisfy these assumptions.

${ }^{8}$ It may be the case that employers learn about the employees' productivity level over time. Farber and Gibbons (1996) and Altonji and Pierret (1999) show that employers learn over time, while Bauer and HasikenDeNew (2000) found the exact opposite - learning did not occur over time. 


$$
\begin{aligned}
& \frac{d\left(L_{1}^{1}+L_{2}^{1}\right)}{d \alpha}=\frac{d L_{1}^{1}}{d \alpha}+\frac{d L_{2}^{1}}{d \alpha}= \\
& -\frac{1}{A}\left[\frac{\partial^{2} \operatorname{Pr}_{2}}{\partial L_{2}^{1} \partial \alpha}\left(-\frac{\partial^{2} \operatorname{Pr}_{1}}{\partial L_{2}^{1} \partial L_{1}^{1}}+\frac{\partial^{2} \operatorname{Pr}_{1}}{\partial L_{1}^{2}}\right)+\frac{\partial^{2} \operatorname{Pr}_{1}}{\partial L_{1}^{1} \partial \alpha}\left(-\frac{\partial^{2} \operatorname{Pr}_{2}}{\partial L_{2}^{1} \partial L_{1}^{1}}+\frac{\partial^{2} \operatorname{Pr}_{2}}{\partial L_{2}^{12}}\right)\right] \\
& \text { where } A=\frac{\partial^{2} \operatorname{Pr}_{1}}{\partial L_{1}^{12}} \frac{\partial^{2} \operatorname{Pr}_{2}}{\partial L_{2}^{12}}-\frac{\partial^{2} \operatorname{Pr}_{1}}{\partial L_{1}^{1} \partial L_{2}^{1}} \frac{\partial^{2} \operatorname{Pr}_{2}}{\partial L_{1}^{1} \partial L_{2}^{1}} .
\end{aligned}
$$

The sign of (7) is not clear. In an attempt to understand the effect of a change in the employer's information level on the workers' investment in promotion-seeking activities, let us first consider the symmetric case:

$$
\text { If } \frac{\partial^{2} \operatorname{Pr}_{1}}{\partial L_{1}^{12}}=\frac{\partial^{2} \operatorname{Pr}_{2}}{\partial L_{2}^{12}} \text { and } \frac{\partial^{2} \operatorname{Pr}_{1}}{\partial L_{1}^{1} \partial L_{2}^{1}}=\frac{\partial^{2} \operatorname{Pr}_{2}}{\partial L_{1}^{1} \partial L_{2}^{1}} \text { then } \frac{d\left(L_{1}^{1}+L_{2}^{1}\right)}{d \alpha}=-\frac{\frac{\partial^{2} \operatorname{Pr}_{i}}{\partial L_{i}^{1} \partial \alpha}}{\frac{\partial^{2} \operatorname{Pr}_{2}}{\partial L_{2}^{12}}+\frac{\partial^{2} \operatorname{Pr}_{1}}{\partial L_{2}^{1} \partial L_{1}^{1}}} . \quad \text { By }
$$
assumption, it holds that $\frac{\partial^{2} \operatorname{Pr}_{j}}{\partial L_{j}^{1}}<0$. If $\frac{\partial^{2} \operatorname{Pr}_{j}}{\partial L_{i}^{1} \partial L_{j}^{1}}<0$ and an increase in the employer's level of information regarding the workers' productivity increases the marginal effect of investment in promotion-seeking activities, such that, $\frac{\partial^{2} \operatorname{Pr}_{i}}{\partial L_{i}^{1} \partial \alpha}>0$, then the total amount of time invested in them would increase. On the other hand, if the employer's level of information is sufficiently high, then $\frac{\partial^{2} \operatorname{Pr}_{i}}{\partial L_{i}^{1} \partial \alpha}<0$. Thus, the total amount of time invested in promotionseeking activities would decrease.

Note that as $\operatorname{Pr}_{i}+\operatorname{Pr}_{j}=1$ it is clear that $\mathrm{A}>0$. The sign of $\frac{\partial\left(L_{1}^{1}+L_{2}^{1}\right)}{\partial \alpha}$, therefore, depends on the sign of $\frac{\partial^{2} \operatorname{Pr}_{i}}{\partial L_{i}^{1} \partial \alpha}$ :

Thus, given two none identical workers, as shown above, it may well be the case that as the employer's level of information regarding the employees' productivity levels increases (up to a certain limit), the total promotion-seeking activities in the firm would also increase.

The reason for this is that increasing the employer's information level may require more activity by one worker to convince the employer that information is incorrect. Such activities are, of course, costly to the firm. If the workers would be identical then increasing the information the employer has regarding the workers' productivity levels would not have any effect on the workers investments. 
In order to understand the effect of these assumptions, a more specific probability function is now used.

\subsubsection{Example: Luce's (Multinomial) Logit Model}

Luce's (Multinomial) Logit Model postulates that the probability of an individual choosing a certain alternative, $a \in S, \operatorname{Pr}_{a}$, is given by:

$$
\operatorname{Pr}_{a}=\frac{e^{q_{a} u(a)}}{\sum_{b \in s} e^{q_{b} u(b)}}
$$

where the parameter, $q_{a}$, represents the employer's preferences (discrimination, or in the present context, the worker's rent-seeking ability). If $q_{b}=0$ for all $b$, then the probability of being promoted is equal for all the employees. The uncertainty increases if the employer does not have full information regarding the employee's real contribution to the firm's profits. In this setting, $u(a)$ is the value attributed by the employer to the worker's productivity level. As stated above, employees invest effort in rent-seeking activities to hide or reveal both their own and their opponents' actual productivity levels from their employers. The utility the employer attributes to worker $i$ is given by $u\left(v_{i}, L_{i}{ }^{l}\right)$. To simplify the calculations and obtain a closed form, let the utility be the logarithmic function, such that $u\left(v_{i}, L_{i}{ }^{1}\right)=\operatorname{Ln}\left(v_{i}^{\alpha} L_{i}{ }^{1}\right)$. Thus, the utility increases with the employee's increased investment in rent-seeking activity. As the employees' investment level increases, they become more adept at hiding or revealing their true level of activity and posing in the guise of productive workers. The $\alpha$-values represent the employer's level of information regarding the worker's productivity level and/or the weight the employer decides to assign to it. As $\alpha$ increases, the employer puts greater emphasis on the worker's productivity level. If $\alpha=0$, the employer does not have any information regarding the worker's productivity level and, thus, the utility depends only on the worker's investment in rent-seeking activities. If $\alpha=\infty$, the employer has full information about the employees' productivity levels, which is exclusively used to make decisions about promotion. This gives the following contest-success function, in which the worker $i$ 's probability of success in competing against $j$ is given by:

$$
\operatorname{Pr} o b_{i}\left(L_{i}, L_{j}\right)=\frac{d_{i} L_{i}^{1} v_{i}^{\alpha}}{d_{i} L_{i}{ }^{1} v_{i}^{\alpha}+d_{j} L_{j}{ }^{1} v_{j}^{\alpha}} \forall i \neq j, \quad i, j=1,2 \text { and } \alpha \geq 0
$$

where $e^{q_{i}}=d_{i}$ represents the employee's rent-seeking ability.

The contest success function is a variant of Tullock's (1980) non-discriminating rule (see also Hirshleifer, 1989 and Hillman and Riley, 1989). The probability of winning the contest is, therefore, determined by the following variables:

a. Investment levels in rent-seeking activities aimed at earning promotion, $L_{i}$,

$b$. The candidates' rent-seeking abilities, $d_{i}$,

c. The candidates' productivity levels, $v_{i}$,

$d$. The amount of information available to the employer regarding the worker's productivity level, $\alpha$. 
Thus, $\frac{\partial \operatorname{Pr} o b_{i}\left(L_{i}{ }^{1}, L_{j}{ }^{1}\right)}{\partial L_{i}{ }^{1}}>0, \quad \frac{\partial \operatorname{Pr} o b_{i}\left(L_{i}{ }^{1}, L_{j}{ }^{1}\right)}{\partial L_{j}}<0, \quad \frac{\partial \operatorname{Pr} o b_{i}\left(L_{i}{ }^{1}, L_{j}{ }^{1}\right)}{\partial d_{i}}>0$,

$\frac{\partial \operatorname{Pr} o b_{i}\left(L_{i}{ }^{1}, L_{j}{ }^{1}\right)}{\partial d_{j}}<0$ and $\frac{\partial \operatorname{Pr} o b_{i}\left(L_{i}{ }^{1}, L_{j}{ }^{1}\right)}{\partial v_{i}}>0, \frac{\partial \operatorname{Pr} o b_{i}\left(L_{i}{ }^{1}, L_{j}{ }^{1}\right)}{\partial v_{j}}<0$

\section{Equilibrium}

Each worker maximizes his/her expected income/utility by choosing the extent of promotion/rent-seeking activities ${ }^{9}$. The expected income is determined by the Nash equilibrium for the rent-seeking choices, which follows for worker $i$, from:

$$
\frac{\partial E\left(I_{i}\right)}{\partial L_{i}^{1}}=-v_{i}+\left(p_{i}-f_{i}\left(v_{i}, d_{i}\right)\right) \frac{d_{i} d_{i} v_{i}^{\alpha} v_{i}^{\alpha} L_{j}^{1}}{\left(d_{j} v_{j}^{\alpha} L_{j}^{1}+d_{i} v_{i}^{\alpha} L_{i}^{1}\right)^{2}}
$$

and $\frac{\partial E\left(I_{i}\right)}{\partial L_{i}^{2}}=-v_{i}+\frac{\partial R_{i}}{\partial L_{i}^{2}}=0$.

The second-order conditions are satisfied. ${ }^{10}$

Assuming an internal solution yields:

$$
L_{i}^{1}=\frac{v_{i}^{\alpha} v_{j}^{\alpha+1} d_{i} d_{j}\left(p_{j}-f_{j}\right)\left(p_{i}-f_{i}\right)^{2}}{\left(\left(p_{i}-f_{i}\right) d_{i} v_{i}^{\alpha} v_{j}+\left(p_{j}-f_{j}\right) d_{j} v_{i} v_{j}^{\alpha}\right)^{2}} \quad \forall i \neq j, i, j=1,2
$$

Let us now look at the effect on the total promotion-seeking activities in the firm, given an increase in the employer's information about the worker's productivity: $\frac{d\left(L_{1}^{1}+L_{2}^{1}\right)}{d \alpha}$. Using (11), we obtain:

$$
\frac{d\left(L_{1}^{1}+L_{2}^{1}\right)}{d \alpha}=-B\left[d_{2} v_{2}^{\alpha-1}\left(p_{2}-f_{2}\right)-d_{1} v_{1}^{\alpha-1}\left(p_{1}-f_{1}\right)\right]\left[\log \left(v_{2}\right)-\log \left(v_{1}\right)\right]
$$

where

$$
B=\frac{\left(p_{1}-f_{1}\right)\left(p_{2}-f_{2}\right) v_{1}^{\alpha+1} v_{2}^{\alpha+1}\left(\left(p_{1}-f_{1}\right) v_{2}+\left(p_{2}-f_{2}\right) v_{1}\right)}{\left(d_{1} v_{1}^{\alpha} v_{2}\left(p_{1}-f_{1}\right)+d_{2} v_{1} v_{2}^{\alpha}\left(p_{2}-f_{2}\right)\right)^{3}}>0
$$

Without loss of generality, assume $v_{1}>v_{2}$, and thus:

\footnotetext{
${ }^{9}$ It is not clear that the results would be different from those presented here if an individual could change the investment level during the course of the contest on receiving new information (see Epstein, 1996).

10 The second-order condition: $\frac{\partial^{2} E\left(I_{i}\right)}{\partial\left(L_{i}^{1}\right)^{2}}<0$ and $\frac{\partial^{2} E\left(I_{i}\right)}{\partial\left(L_{i}^{2}\right)^{2}}<0 \quad \forall i \neq j$.
} 


$$
\frac{d\left(L_{1}^{1}+L_{2}^{1}\right)}{d \alpha}>0 \text { if }\left(\frac{v_{2}}{v_{1}}\right)^{\alpha-1}<\frac{\left(p_{1}-f_{1}\right) d_{1}}{\left(p_{2}-f_{2}\right) d_{2}}
$$

Note that for $\left(\frac{v_{2}}{v_{1}}\right)^{\alpha-1}<1$ and $p_{1}>p_{2}$, the direction of (13) is still not clear. If the productive worker receives a higher increase in wages from one rung to next, while the other worker is very efficient in promotion-seeking activities, the total amount of resources spent on promotion-seeking may increase with an increase in the manager's information. The reason behind this is that the less productive worker would have to hide his or her productivity level even more in the new situation. However, if the increase of wages for the productive worker from one rung to the next is sufficiently high (relative to that of the worker with low productivity and his rent seeking ability), then the total investment in promotion-seeking activities would decrease. Moreover, as the information level increases, there is a greater probability of a decrease in the total investment.

From (13), the following conclusion can be drawn:

$$
\frac{d\left(L_{1}^{1}+L_{2}^{1}\right)}{d \alpha}<0 \text { iff } \alpha>1+\frac{\operatorname{Ln}\left[\frac{\left(p_{1}-f_{1}\right) d_{1}}{\left(p_{2}-f_{2}\right) d_{2}}\right]}{\operatorname{Ln}\left[\frac{v_{2}}{v_{1}}\right]}
$$

Thus, it is clear that, if the productive worker is a better promotion seeker or the increase in their wages is sufficient from one rung to the next, then increasing the manager's information regarding his employee's productivity level would lead to a decrease in total investment in promotion-seeking activities. Otherwise, total investment in promotion-seeking activities may increase. However, if the level of information is sufficiently high, then the total investment would decrease. Note that of the workers would be identical increasing the information level would have no effect on the rent seeking activities of the workers.

To conclude:

Give that the workers are not identical, as the employer's information regarding the workers' productivity level increases, total investment in production-seeking activities may either increase or decrease. If the information level is sufficiently high, then total investment in promotion-seeking activities decreases (see figure 1). 
Figure 1. Information and effort

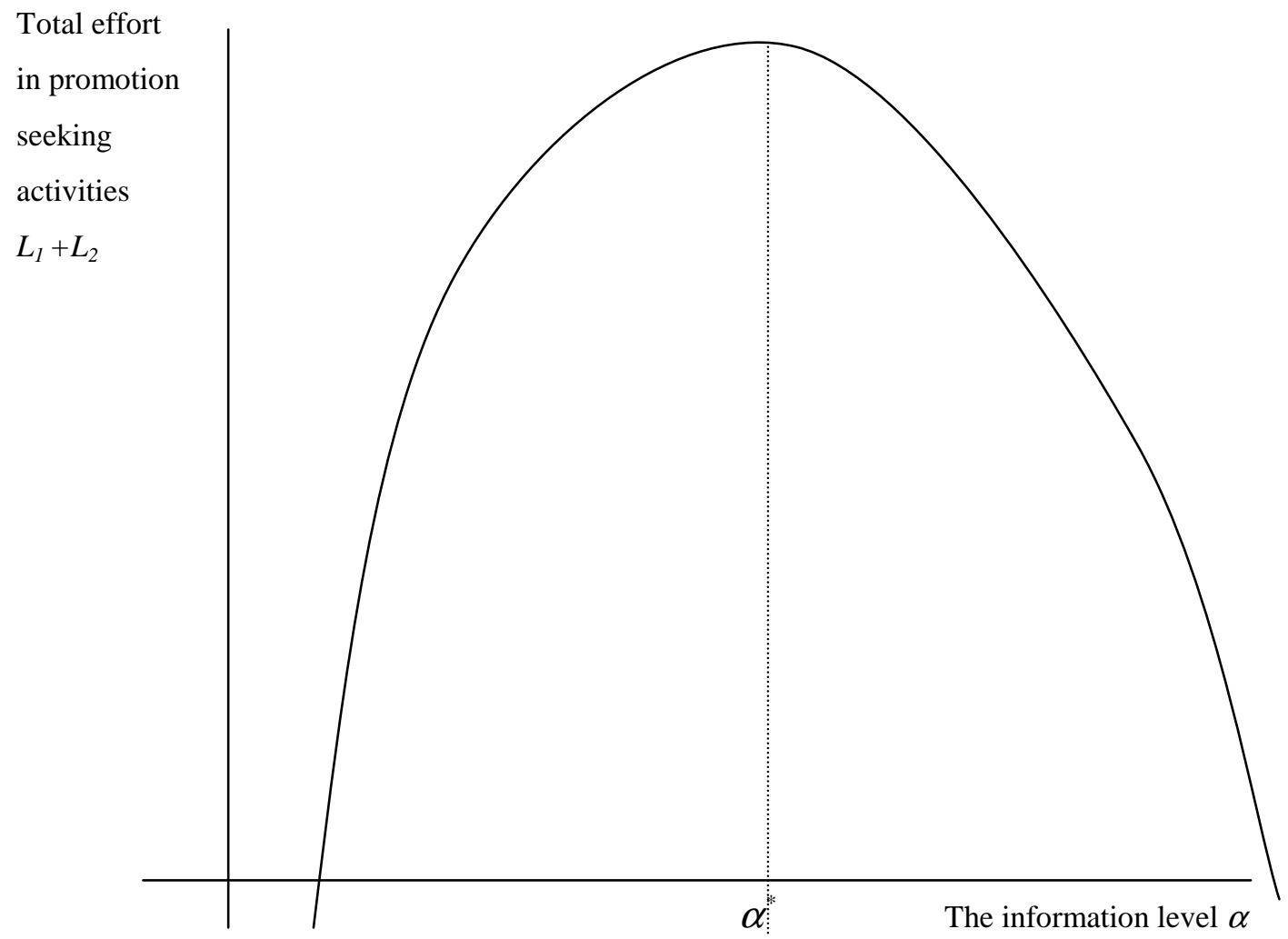

\section{Conclusions}

This paper considered the case in which the workers in a firm can engage in rent- promotionseeking activities to increase their income and climb the rungs of the firm's ladder. Employers may or may not design such political contests, however the workers may well believe that such contests exists (see Cleveland and Murphy, 1992; Altman, Vanlenzi and Hodgetts, 1985 and Tziner, 1999). The effect of the employer's information level, with regard to the individual worker's productivity level on the workers' total promotion-seeking activities, was investigated. Under certain conditions, increasing the employer's information level regarding two none identical workers was shown to increase the total time the workers invest in attempting to influence their employer's decisions. The intuition behind this result is that, as the employer receives more information with the employees' knowledge, it would induce the latter to invest more time in convincing the employer that this information is true or false, depending on their different productivity levels.

Acknowledgements. Financial support from the Adar Foundation of the Economics. I am grateful to Laura Shuck for many helpful suggestions and comments and to an anonymous referee for constructive comments. 


\section{References}

Alman S., Valenzi, E. and Hodgetts, R.M. (1985) Organization behavior: theory and practice, Academic Press, Orlando, FL.

Altonji, J.G. and Pierret C.R. (1999) Employer learning and statistical discrimination, unpublished manuscript, Northwestern University.

Bauer T.K. and Hasken-DeNew, J.P. (2000) Employer learning and the returns to schooling, IZA discussion paper no 146.

Beckmann, M.J. (1978) Rank in Organizations, Berlin: Springer-Verlag.

Cleveland, J.N. and Murphy, K.R. (1992) Analyzing performance appraisal as goal-directed behavior, Research in Personnel and Human Resources Management, 10, 121-185.

Epstein, G.S. (1996) Changing a decision taken under incomplete information during the process of execution, Journal of Economic Behavior and Organization, 29, 323-329.

Epstein, G.S. and Spiegel, U. (1997) Monitoring within the firm and manager relations, International Journal of the Economics of Business, 4(1), 51-62.

Epstein, G.S. and Spiegel, U. (2001) Natural inequality, productivity and economic growth, Journal of Labour Economics, 8, 463-473.

Epstein, G.S. and Nitzan, S. (2004) Strategic restraint in contests, European Economic Review, 48, 201-210.

Epstein, G.S. and Nitzan, S. (2007) Endogenous Public Policy and Contests, Springer.

Epstein, G.S. and Mealem, Y. (2012) Cooperation and effort in group contests', Economics Bulletin, 32(1), 624-638.

Fama, E.F. (1980) Agency problems and the theory of the firm, Journal of Political Economy, 88(2), 288-307.

Farber, H.S. and Gibbons, R. (1996) Learning and wage dynamics, Quarterly Journal of Economics, 111, 1007-1047.

Hillman, A.L. and Riley, J.G. (1989) Politically contestable rents and transfers, Economics and Politics, 1, 7-39.

Hillman, A.L. and Katz, E. (1987) Hierarchical structure and the social costs of bribes and transfers, Journal of Public Economics, 129-142.

Hirshleifer, J. (1989) Conflict and rent seeking success functions: ratio vs difference model of relative success, Public Choice, 101-112.

Lazear, E.P. (1996) Personnel Economics, $2^{\text {nd }}$ ed., MIT Press Cambridge.

Lazear, E.P. and Rosen, S. (1981) Rank-order tournaments as optimum labor contracts, Journal of Political Economy, 89(5), 841-864.

Luce, R.D. (1959) Individual Choice Behavior: A Theoretical Analysis, Wiley.

Milgrom, P.R. and Roberts, J. (1992) Economics, Organization and Management, PrenticeHall.

Nitzan, S. (1994) Modelling rent-seeking contests, European Journal of Political Economy, 10(1), 41-60.

Radner, R. (1993) Hierarchy: the economics of managing, Journal of Economic Literature, $1382-1415$.

Rosen S. (1986) Prizes and incentives in elimination tournaments, The American Economic Review, 76(4), 701-715.

Sheshinski, E. (2002) Bounded rationality and social optimal limits on choice: an example, Hebrew University Jerusalem.

Skaperdas, S. (1996) Contest success functions, Economic Theory, 7, 283-290. 
Tullock, G. (1980) Efficient rent seeking, in J.M. Buchanan, R.D. Tollison and G. Tullock (eds) Toward a Theory of the Rent Seeking Society, Texas A@T Press, College Station TX.

Tversky, A. (1969) Intransitivity and preferences, Psychological Review, 76, 31-48.

Tversky, A. (1972) Elimination by aspects: a theory of choice, Psychological Review, 79, 281 299.

Tziner, A. (1999) The relationship between distal and proximal factors and the use of political considerations in performance appraisal, Journal of Business and Psychology, 14(1), 217-231.

Tziner, A., Latham, G.P., Prince, B.S. and Haccoum, R.R. (1996) Development and validation of a questionnaire for measuring political considerations in performance appraisal, Journal of Organization Behavior, 17, 179-190. 